\title{
SiGe relaxation on silicon-on-insulator substrates: An experimental and modeling study
}

\author{
E. M. Rehder ${ }^{\mathrm{a})}$ \\ Materials Science Program, University of Wisconsin-Madison, Madison, Wisconsin 53706 \\ C. K. Inoki and T. S. Kuan \\ Department of Physics, University at Albany, 1400 Washington Ave, Albany, New York 12222 \\ T. F. Kuech ${ }^{\text {b) }}$ \\ Department of Chemical Engineering, University of Wisconsin-Madison, Madison, Wisconsin 53706
}

(Received 18 March 2003; accepted 30 September 2003)

\begin{abstract}
The strain relaxation behavior of $\mathrm{Si}_{0.82} \mathrm{Ge}_{0.18}$ films on silicon-on-insulator (SOI) substrates was investigated for films grown beyond the critical thickness and strain-relaxed during growth and metastable films, grown beyond the critical thickness, which relaxed during subsequent thermal annealing. The thickness of the top silicon layer of the SOI substrate was varied over a range from $40 \mathrm{~nm}$ to $10 \mu \mathrm{m}$. In all cases, the SiGe film relaxation occurred via the nucleation and propagation of dislocations with the same onset of film relaxation and same relaxation rate for both SOI and bulk Si substrates. The SOI substrate does not serve as a compliant substrate but does alter the dislocation structure and motion. The buried amorphous oxide layer in the SOI substrate leads to the relaxation of the dislocation strain field through the removal of the dislocation line tension. This removal of the dislocation line tension drives dislocation motion and leads to the development of strain in the thin Si layer of the SOI substrate. Models of this dislocation behavior for SiGe growth on the SOI substrate are presented and calculation of the equilibrium strain of the thin Si substrate layer closely fits the measured strain of several SOI substrates. The article addresses the implications of the modified dislocation structure and kinetics for film relaxation on SOI substrates. (C) 2003 American Institute of Physics. [DOI: 10.1063/1.1628406]
\end{abstract}

\section{INTRODUCTION}

Film strain is a critical parameter controlling the electrical and optical properties of epitaxial semiconductor thin films. A wide range of properties within the same materials system can be accessed by manipulating strain in addition to film composition. Strained-layer structures have been used in a wide variety of device structures in both elemental and compound semiconductor materials. In the case of SißiGe technology, the modification to the local electronic structure has been effectively used in heterojunction bipolar and heterojunction field effect transistors. Two key heterojunction device parameters are band offsets and carrier mobilities, and both parameters are controlled by the detailed strain state of the heterojunction layers. ${ }^{1,2}$ The choice of substrate and film composition will determine the strain in the device structure. As an alternative to a Si substrate, compositionally graded strain-relaxed layers of $\mathrm{SiGe}$, grown on a Si substrate, can be used to adjust the lattice parameter of the surface layer to possess a value between that of $\mathrm{Si}$ and $\mathrm{Ge}$. Such substrates offer opportunities in device design and materials integration. This lattice constant increase and film relaxation results from the formation and motion of dislocations. Pseudomorphic Si- and Ge-rich films can then be deposited, strained to the lattice constant of the relaxed buffer layer. A Si-rich SiGe

${ }^{a)}$ Current address, Kopin Corporation, Taunton, MA 02780.

${ }^{b}$ Electronic mail: kuech@engr.wisc.edu film grown on a relaxed SiGe film will be under a tensile strain with a band offset to the SiGe layer that allows for electron confinement in the Si layer. Conversely, holes will be confined in Ge-rich layers that are the compressively strained relative to a lower Ge composition $\mathrm{SiGe}$ relaxed film. This ability to control carrier placement has been exploited to form modulation-doped field effect transistors as well as electron- and hole-based resonant tunneling diodes. ${ }^{2-4}$ In addition, the lattice matching of relaxed Ge to $\mathrm{GaAs}$ has been utilized to fabricate InGaP visible lightemitting diodes on $\mathrm{Si}$ substrates. ${ }^{5}$

The increase in the lattice constant of an epitaxial $\mathrm{SiGe}$ film, as it develops from a pseudomorphic to a partially or fully strain-relaxed layer, is accomplished by the introduction and extension of misfit dislocations at the film§ubstrate interface. The total length of the misfit dislocations at this interface governs the absolute amount of film relaxation. The ends of these misfit dislocations terminate at the film surface by means of threading segments. These threading segments extend from the plane of the interface to the surface with a change in the dislocation line direction. These threading segments can penetrate active device areas in subsequently grown layers and degrade carrier mobility, increase junction leakage currents, and produce variations in the threshold voltage of field effect transistors. ${ }^{6-8}$ Numerous research efforts have pursued threading dislocation reduction over the past decade and have demonstrated considerable achievements. A wide variety of growth methods involving the 
growth of different buffer layer structures, altering growth temperatures, and the use of surfactants have reduced the threading dislocation density (TDD) of films containing $20 \%-30 \%$ Ge to $10^{4}-10^{5} \mathrm{~cm}^{-2} \cdot{ }^{9-12}$

In this study, we have investigated the influence of a silicon-on-insulator (SOI) substrate on the SiGe film relaxation process. Reports have indicated reductions in the TDD by a factor greater than $10^{5}$ between identical growths on bulk Si and SOI substrates. ${ }^{13-15}$ Explanations for this behavior have differed. Legoues, et al. ${ }^{13,14}$ described the improvement as due to compliant substrate effects, where the buried $\mathrm{SiO}_{2}$ layer allows the top $\mathrm{Si}$ and $\mathrm{SiGe}$ layers to share the misfit strain decoupled from the underlying thick substrate. The dislocation image force derived from the buried oxide layer was also suggested as playing a key role. ${ }^{15}$ Both of these sets of experiments employed SOI substrates having a top $\mathrm{Si}$ layer, which will be referred to as the $\mathrm{Si}$-SOI layer, that was less than $60 \mathrm{~nm}$ thick. Both mechanisms for the defect reduction are also critically dependent on the $\mathrm{Si}-\mathrm{SOI}$ being thin, either near the film critical thickness $(22 \mathrm{~nm}$ for $18 \% \mathrm{Ge}$ ) or within the range of the image force, $<40 \mathrm{~nm}$. In order to determine the specific dislocation mechanisms occurring during film relaxation, we have focused on SOI substrates having a wide range of Si-SOI layer thicknessess, i.e., $40,70,330$, or $10000 \mathrm{~nm}$ and the use of ultrahigh vacuum chemical vapor deposition for SiGe growth. ${ }^{16}$

Throughout this investigation, a single composition, $\mathrm{Si}_{0.82} \mathrm{Ge}_{0.18}$, was studied. The film composition of $\sim 18 \% \mathrm{Ge}$ was chosen in order to allow control over the growth morphology for the range of growth temperatures used here. SiGe growth at high temperatures or at a high Ge film composition favors a three-dimensional (3D) island growth mode. ${ }^{17} \mathrm{An}$ islanded surface lowers the activation barrier for dislocation nucleation and leads to the rapid formation of a high density of dislocations. ${ }^{18}$ By maintaining a smooth film, dislocation nucleation is kinetically limited and dislocationfree films can be grown well beyond the critical thickness for dislocation formation allowing for the exploration of the influence of the SOI substrate under a variety of growth and processing conditions.

Several aspects of dislocation motion and the associated strain relaxation of a $\mathrm{SiGe}$ film on a SOI substrate were investigated. Companion samples of identical SiGe films grown on bulk Si substrates were used throughout the study as a control and for comparison. The role of growth morphology, specifically the transition from two-dimensional (2D) to 3D growth modes, was investigated. The strain relaxation of pseudomorphic SiGe films through postgrowth ex situ high-temperature annealing was determined. These results are compared to the experimentally determined film relaxation processes occurring during the growth of substantially thicker films, grown above the thickness for dislocation introduction during growth. Throughout the study, x-ray diffraction was used to measure the strain state of the various $\mathrm{SiGe}$ and Si layers. Atomic force microscopy (AFM) quantified the surface morphology of the films at various stages of growth and annealing. The dislocation distribution throughout the samples was determined by cross-sectional transmis- sion electron microscopy (XTEM) and plan-view transmission electron microscopy (PVTEM)

A major experimental finding in this study was that the $\mathrm{Si}-\mathrm{SOI}$ layer becomes strained following relaxation of the SiGe films. This strain is a product of dislocation motion in the $\mathrm{Si}-\mathrm{SOI}$ layer. The extent and details of this motion is the result of the interaction of the lattice-mismatch-derived dislocations with the amorphous oxide. This interaction results in the removal of the dislocation strain field present at the $\mathrm{Si}-\mathrm{SOI}-$ oxide interface. In addition to producing strain in the $\mathrm{Si}-\mathrm{SOI}$, the reduced dislocation line tension removes the critical thickness condition and increases dislocation velocities.

\section{EXPERIMENTAL PROCEDURES}

\section{A. SiGe growth and growth morphology}

Film growth was carried out in a cold-wall, ultrahigh vacuum chemical vapor deposition system using $10 \% \mathrm{SiH}_{4}$ and $5 \% \mathrm{GeH}_{4}$ diluted in $\mathrm{H}_{2}$ at 23 mTorr. ${ }^{19}$ Films were grown having a composition of $\sim 18 \%$ Ge. The composition reproducibility of this growth system for these samples is $x_{\mathrm{Ge}}$ $=0.18 \pm 0.005$. This film composition allows for control of the growth morphology with temperature. SiGe films were grown to a thickness of $150 \mathrm{~nm}$ at 550,630 , and $670{ }^{\circ} \mathrm{C}$, whereas the film grown at $700{ }^{\circ} \mathrm{C}$ roughened immediately and was only grown to $6 \mathrm{~nm}$. The SiGe film surface was monitored during growth with differentially pumped reflection high-energy electron diffraction (RHEED) ${ }^{20}$ Following growth, AFM was used to measure the surface roughness and the size and distribution of the island.

\section{B. Ex situ film relaxation}

Metastable and pseudomorphic $\mathrm{Si}_{0.82} \mathrm{Ge}_{0.18}$ films were grown to $150 \mathrm{~nm}$ on bulk Si, $40 \mathrm{~nm} \mathrm{SOI}$, and $70 \mathrm{~nm}$ SOI substrates. All of the SOI substrates used in this work were bonded, not separation by implantation of oxygen- or SIMOX-based, SOI wafers. This film thickness of $150 \mathrm{~nm}$ is seven times greater than the critical thickness of $22 \mathrm{~nm}$, yet the films remain fully strained, as verified by $\mathrm{x}$-ray measurements. Following growth at $630^{\circ} \mathrm{C}$ and the initial x-ray characterization, these films were annealed under $\mathrm{N}_{2}$ for $1 \mathrm{~h}$ at temperatures as high as $1050^{\circ} \mathrm{C}$ to induce relaxation and after which they were again characterized by x-ray diffraction. Reciprocal space maps (RSMs) of the (004) reflections were used to measure the film relaxation and associated lattice tilts. A slit in front of the x-ray detector limited the detector acceptance angle to $325 \mathrm{arcsec}$ during the acquisition of the RSMs.

\section{In situ film relaxation}

In the another set of experiments, uniform $\mathrm{Si}_{0.82} \mathrm{Ge}_{0.18}$ films were relaxed in situ by growth at $630^{\circ} \mathrm{C}$ to a substantially greater thickness than used in the ex situ studies. Substrates for these films included bulk Si, $40 \mathrm{~nm}$ SOI, $70 \mathrm{~nm}$

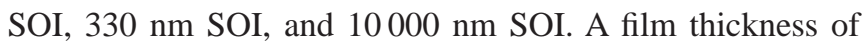
$150 \mathrm{~nm}, 340 \mathrm{~nm}, 765 \mathrm{~nm}$, and $1200 \mathrm{~nm}$ was selected to span the realized levels of film relaxation from $0 \%$ to $80 \%$. Analysis of the grown layers consisted of $\mathrm{x}$-ray diffraction, AFM, 


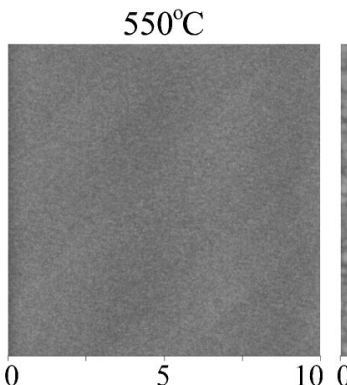

(a)

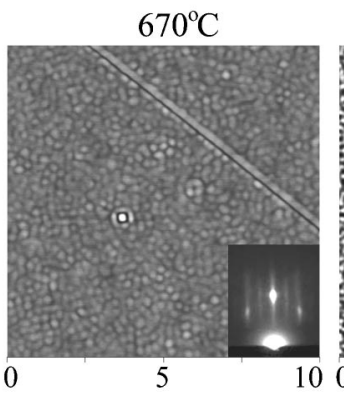

(c)

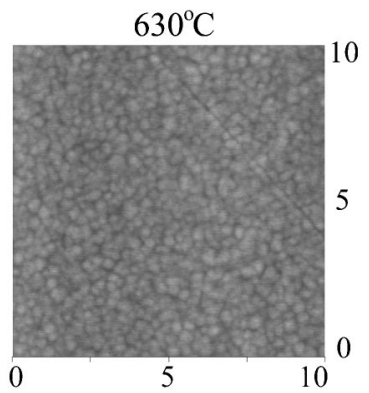

(b)

$700^{\circ} \mathrm{C}$

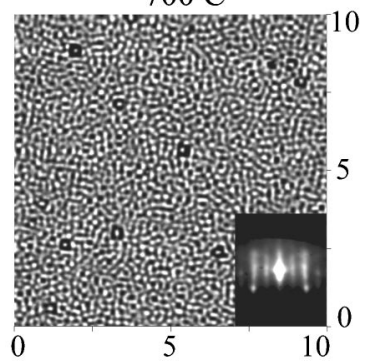

(d)
FIG. 1. AFM scans of $150 \mathrm{~nm} \mathrm{SiGe} \mathrm{samples} \mathrm{grown} \mathrm{at} 550{ }^{\circ} \mathrm{C}\left(\right.$ a), $630^{\circ} \mathrm{C}$ (b), $670{ }^{\circ} \mathrm{C}(\mathrm{c})$, and $700{ }^{\circ} \mathrm{C}(\mathrm{d})$. All the images are $10 \times 10 \mu \mathrm{m}$ and plotted on a $15 \mathrm{~nm}$ height (grayscale) scale. The rms roughness of the samples is $0.3,0.4,0.7$, and $3.0 \mathrm{~nm}$ exhibiting an increase with growth temperature. The insets to (c) and (d) are in situ [110] RHEED diffraction patterns. and transmission electron microscopy (TEM). Film relaxation was calculated using the film-to-substrate peak separation from the [004] data and the composition from the 150 $\mathrm{nm}$ nonrelaxed samples grown under identical growth conditions. Only the thicker films from this sample set provided sufficient $\mathrm{x}$-ray diffracted intensity to allow the acquisition of RSMs with the higher resolution analyzer crystal $(<5 \operatorname{arcsec})$.

\section{EXPERIMENTAL RESULTS}

\section{A. Control of SiGe islanding through growth temperature}

The relationship between growth morphology and growth temperature observed for a series of $150 \mathrm{~nm}$ thick SiGe films is shown in the AFM images of Fig. 1 for films grown at different temperatures. These surfaces, as measured by AFM, have a root-mean-square (rms) roughness of 0.3 , 0.4 , and $0.7 \mathrm{~nm}$ for growth at 550,630 , and $670{ }^{\circ} \mathrm{C}$ respectively. The insets in Figs. 1(c) and 1(d) present the in situ RHEED diffraction patterns from the SiGe $150 \mathrm{~nm}$ films. The films grown at a temperature below $670{ }^{\circ} \mathrm{C}$ yielded the same RHEED diffraction pattern as shown in the inset of Fig. 1(c). The single intensity maximum on each vertical streak indicates diffraction from a flat $2 \mathrm{D}$ surface. The RHEED pattern from the film grown at $700{ }^{\circ} \mathrm{C}$, [Fig. 1(d) inset] exhibits multiple maxima on each streak, indicating $3 \mathrm{D}$ diffraction and hence the presence of island growth. This surface roughness develops after only $6 \mathrm{~nm}$ of film growth in contrast to the smooth surface achieved on the $150 \mathrm{~nm}$ thick
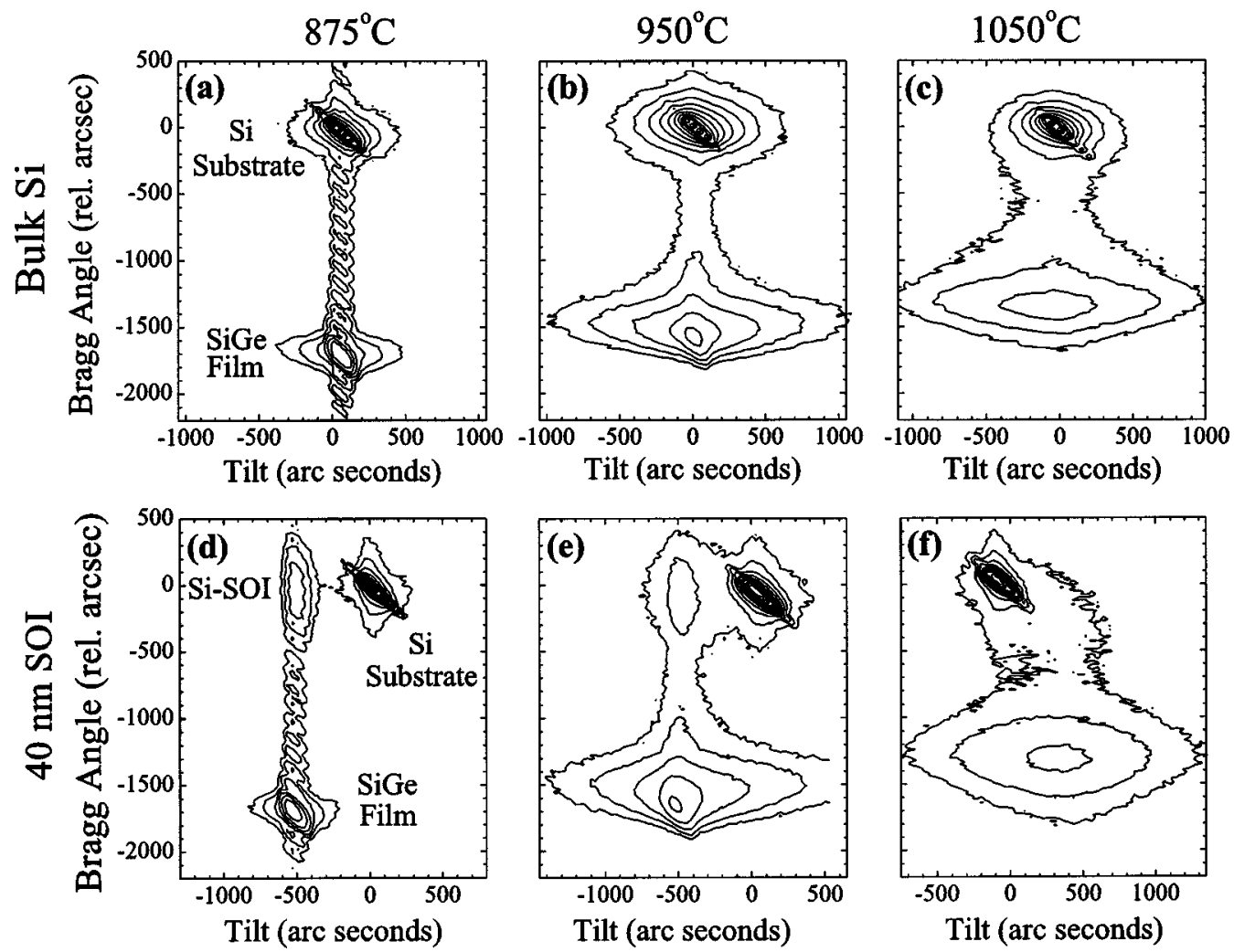

FIG. 2. RSMs of the (004) reflection of $150 \mathrm{~nm} \mathrm{SiGe} \mathrm{films} \mathrm{on} \mathrm{both} \mathrm{bulk} \mathrm{Si} \mathrm{[(a),} \mathrm{(b),} \mathrm{and} \mathrm{(c)]} \mathrm{and} 40 \mathrm{~nm} \mathrm{SOI} \mathrm{[(d),} \mathrm{(e),} \mathrm{and} \mathrm{(f)]} \mathrm{substrates} \mathrm{after} \mathrm{annealing.} \mathrm{SiGe}$ film relaxation is observed following annealing at $950^{\circ} \mathrm{C}$ and $1050^{\circ} \mathrm{C}$. 
TABLE I. Summary of x-ray data from annealed films listing percent relaxation, (FWHM), and the percent strain in the $\mathrm{Si}-\mathrm{SOI}$ layer for the substrates studied.

\begin{tabular}{cccccc}
\hline \hline $\begin{array}{c}\text { Anneal } \\
\text { temperature } \\
\left({ }^{\circ} \mathrm{C}\right)\end{array}$ & $\begin{array}{c}\text { Substrate } \\
\text { type }\end{array}$ & $\begin{array}{c}\text { SiGe film } \\
\text { thickness }\end{array}$ & $\begin{array}{c}\text { SiGe film } \\
\text { \% relaxation }\end{array}$ & $\begin{array}{c}\text { SiGe film } \\
\text { FWHM }\end{array}$ & $\begin{array}{c}\text { Si-SOI } \\
\% \text { in-plane strain }\end{array}$ \\
\hline 875 & Bulk Si & $150 \mathrm{~nm}$ & 0 & $78.8 \pm 1.3$ & $\ldots$ \\
875 & $40 \mathrm{~nm} \mathrm{SOI}$ & $150 \mathrm{~nm}$ & 0 & $73.5 \pm 0.7$ & 0 \\
950 & Bulk Si & $150 \mathrm{~nm}$ & $15 \pm 2$ & $212 \pm 11.0$ & $\ldots$ \\
950 & $40 \mathrm{~nm} \mathrm{SOI}$ & $150 \mathrm{~nm}$ & $11 \pm 2$ & $185 \pm 7.0$ & $-0.037 \pm 0.004$ \\
950 & $70 \mathrm{~nm} \mathrm{SOI}$ & $150 \mathrm{~nm}$ & $14 \pm 2$ & $219 \pm 12.0$ & $-0.027 \pm 0.004$ \\
1050 & Bulk Si & $150 \mathrm{~nm}$ & $51 \pm 2$ & $850 \pm 22.0$ & $\ldots$ \\
1050 & $40 \mathrm{~nm} \mathrm{SOI}$ & $150 \mathrm{~nm}$ & $46 \pm 2$ & $822 \pm 11.0$ & interdiffused \\
\hline \hline
\end{tabular}

film grown at lower temperatures. AFM micrographs of the sample shown in Fig. 1(d) reveals a dense network of SiGe islands populating the surface with an rms roughness of $3 \mathrm{~nm}$ after only $6 \mathrm{~nm}$ of film growth. While film strain provides a driving force for roughening, the slow surface diffusion at growth temperatures below $700{ }^{\circ} \mathrm{C}$ preserves smooth film morphology. The film-islanding occurring at $700{ }^{\circ} \mathrm{C}$ leads to the rapid nucleation of dislocations. In order to reduce the dislocation nucleation, all subsequent film growths were carried out at $630^{\circ} \mathrm{C}$. This temperature represents a balance between the low temperatures needed to achieve a smooth surface, and hence control over dislocation nucleation, and the elevated growth temperatures required for a high dislocation velocity.

\section{B. Ex situ film relaxation}

Film relaxation due to postgrowth annealing was monitored through changes in the x-ray RSMs. A summary of the $\mathrm{x}$-ray diffraction RSMs of the metastable films following annealing is presented in Fig. 2. A slight initial angular tilt ( $\pm 500 \mathrm{arcs}$ ) across the oxide of the bonded SOI substrate is apparent and allows the bulk $\mathrm{Si}$ substrate and the $\mathrm{Si}-\mathrm{SOI}$ layer to be measured independently. This tilt is a result of the small difference in alignment between the orientation of the handle wafer and the $\mathrm{Si}-\mathrm{SOI}$ layer during manufacture of the SOI substrate. At annealing temperatures of $875^{\circ} \mathrm{C}$, film relaxation was not observed on either the bulk $\mathrm{Si}$ or SOI substrates. Strain relaxation was observed as movement of the $\mathrm{SiGe}$ diffraction peak apparent in the RSMs for samples undergoing the $950^{\circ} \mathrm{C}$ and $1050^{\circ} \mathrm{C}$ anneals. The x-ray data are summarized in Table I. The film relaxation leads to an increase in the crystal tilts within the SiGe layer, producing a broadened peak width and crosshatch that is apparent in AFM images of the film surface in Fig. 3. The progression from a metastable to a relaxed film occurs at the same rate and temperature for the bulk Si, $70 \mathrm{~nm} \mathrm{SOI} \mathrm{(not} \mathrm{shown),} \mathrm{and}$ $40 \mathrm{~nm}$ SOI substrates. The surface morphology of these samples is unchanged between the initial growth surfaces [Figure 1(b)] and after annealing at $875^{\circ} \mathrm{C}$ [Figs. 3(a) and 3(d)]. These metastable films, after annealing, exhibit the very initial stages of crosshatch associated with the strain relaxation processes, with trenches extending hundreds of micrometers in length at a spacing of tens of micrometers. Samples annealed at $950^{\circ} \mathrm{C}$ possessed a densely crosshatched surface, seen in Figs. 3(b) and 3(e). The cross- hatched film surface, when combined with the film relaxation observed in the x-ray diffraction of Figs. 2(b) and 2(e), indicates that a large misfit dislocation density is present in the SiGe films.

Additional information can be gained through monitoring the peak shift in the RSM of the Si-SOI layer. After annealing at $875^{\circ} \mathrm{C}$, the $\mathrm{Si}-\mathrm{SOI}$ layer has the bulk lattice constant of Si. Following the anneal at $950{ }^{\circ} \mathrm{C}$, the SiGe film peak broadens and surface crosshatch appears, due to the introduction and motion of dislocations. The $950{ }^{\circ} \mathrm{C}$ annealed SOI samples also exhibit a small amount of in-plane strain in the Si-SOI layer of $0.047 \%$ and $0.035 \%$ for the 40 and $70 \mathrm{~nm}$ SOI substrates. It is interesting to note that if this tensile strain in the $\mathrm{Si}-\mathrm{SOI}$ layer were attributed to purely compliant substrate effects, associated with a "compliant" oxide layer, a much greater strain would be predicted. A model of a purely compliant substrate would predict strain partitioning between the $\mathrm{SiGe}$ and $\mathrm{Si}-\mathrm{SOI}$ layers which would leave the $\mathrm{Si}-\mathrm{SOI}$ layer with a tensile strain of $0.16 \%$ and $0.11 \%$ for the 40 and $70 \mathrm{~nm}$ SOI substrates, respectively. The observed strain is approximately four times less than that predicted through a purely compliant substrate model. Additionally, the strain in the $\mathrm{Si}-\mathrm{SOI}$ layer only appears with the onset of dislocation-based relaxation of the SiGe film and not simply through thermal annealing alone, as would be expected when the oxide serves to form the compliant medium within the compliant substrate structure.

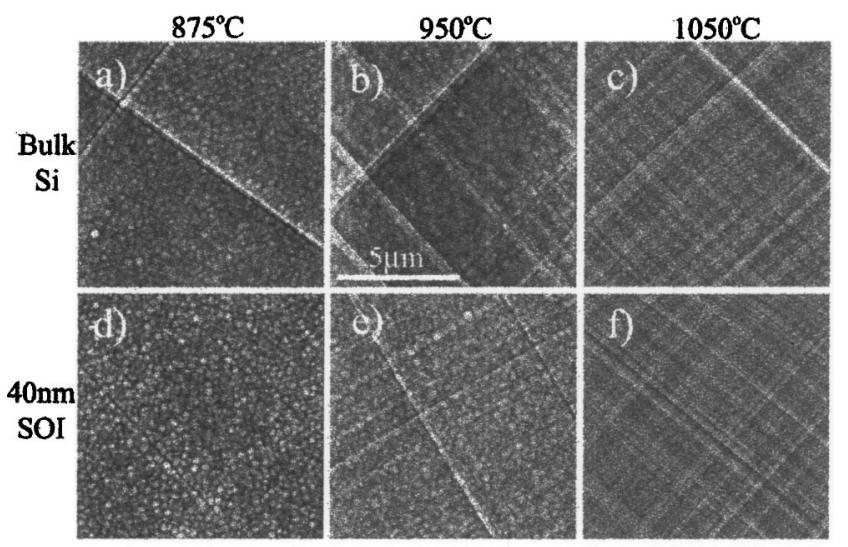

FIG. 3. AFM micrographs of the films after annealing. Crosshatch is observed in samples on both bulk $\mathrm{Si}$ and $\mathrm{SOI}$ substrates which received the $950^{\circ} \mathrm{C}$ and $1050^{\circ} \mathrm{C}$ anneals. 


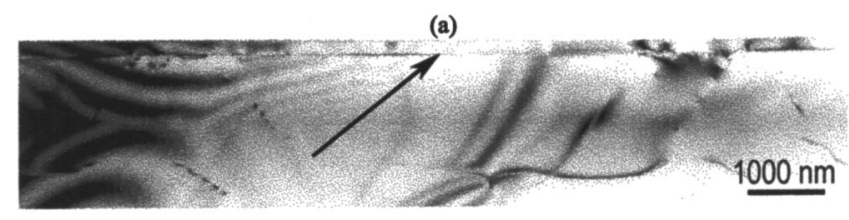

(b)

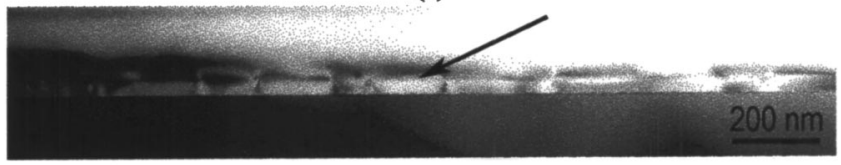

FIG. 4. Cross-sectional micrographs of the (a) bulk Si and (b) $40 \mathrm{~nm} \mathrm{SOI}$ samples following $950{ }^{\circ} \mathrm{C}$ annealing. An arrow indicates the placement of the $\mathrm{SiGe}-\mathrm{Si}$ interface. Substrate dislocations extend several microns into the bulk $\mathrm{Si}$, while on the SOI substrate they cross the SOI layer and terminate at the oxide. Dislocation contrast is not observed at the buried oxide interface of the SOI substrate.

After annealing at $1050{ }^{\circ} \mathrm{C}$, the diffraction peak from the $\mathrm{Si}-\mathrm{SOI}$ layer diminished greatly in intensity and the peak shifted toward the SiGe diffraction peak. This peak shift is due to significant interdiffusion between the $\mathrm{SiGe}$ and $\mathrm{Si}-$ SOI layer that is apparent after annealing at $1050{ }^{\circ} \mathrm{C}$. Numerical simulations of the interdiffusion process confirm that the interdiffusion would lead to a Ge compositional gradient across the $\mathrm{Si}-\mathrm{SOI}$ layer from $18 \% \mathrm{Ge}$ at the $\mathrm{SiGe}-\mathrm{Si}-\mathrm{SOI}$ interface to at least $1 \% \mathrm{Ge}$ at the oxide interface after a $1050^{\circ} \mathrm{C}$ anneal.

The X-ray diffraction and AFM measurements have confirmed the presence of dislocations that relax the SiGe film. XTEM was also carried out on samples annealed at $950^{\circ} \mathrm{C}$ to determine the distribution of these dislocations within the material. Dislocations are easily observed in films on both bulk $\mathrm{Si}$ and SOI substrates as shown in Fig. 4. For films grown on the bulk Si substrate [shown in Fig. 4(a)] dislocations loops appear at least $2 \mu \mathrm{m}$ into the Si substrate. Pairs of associated dislocations on parallel glide planes are observed in the substrate as previously described in Ref. 20. The substrate dislocations in the SOI substrate simply cross the 40 $\mathrm{nm} \mathrm{Si-SOI} \mathrm{layer} \mathrm{to} \mathrm{the} \mathrm{buried} \mathrm{oxide.} \mathrm{There} \mathrm{is} \mathrm{no} \mathrm{dislocation-}$ based contrast along the $\mathrm{Si}-\mathrm{SOI} / \mathrm{SiO}_{2}$ interface in the TEM micrographs. This lack of contrast in the TEM micrographs has been directly observed at room temperature for dislocations at metal/amorphous material interfaces. ${ }^{21-23}$ In these previous studies, the dislocation core was found to dissipate by core-spreading at the interface, reducing the elastic distortion and energy of the dislocation core. This corespreading is likely to be taking place at the $\mathrm{Si} / \mathrm{SiO}_{2}$ interface in this study. The amorphous layer is able to reorient, on the atomic scale, to absorb the displacement of the core leading to a final result that is very similar to the behavior of a dislocation reaching or interacting with a free surface.

While a larger density of dislocations is observed extending into the $\mathrm{Si}-\mathrm{SOI}$ layer than into the companion bulk Si substrate under similar growth conditions, no film threading dislocations were observed in the small areas of the $\mathrm{Si}-$ SOI layer probed by the XTEM, putting an upper limit on the threading dislocation density near $10^{7}$ per $\mathrm{cm}^{2}$. An equivalent density of threading dislocations is observed in the film grown on the bulk Si substrate.

\section{In situ film relaxation}

In the previous series of samples, the $150 \mathrm{~nm}$ films grown on the bulk Si or SOI substrates remain fully strained following growth and cooling to room temperature. An increase in the film thickness to $340 \mathrm{~nm}$ however leads to the initiation of film relaxation on all the substrates during the growth process. The Pendellosung thickness fringes present in the RSMs of Figs. 2(a) and 2(d) diminish in intensity and the SiGe peak broadens as a result of the in situ strain relaxation. The misfit dislocation density is still too low, however, to cause a measurable shift in the diffraction peak position. Film growth to $765 \mathrm{~nm}$ and $1200 \mathrm{~nm}$ did result in observable amounts of strain relaxation as indicated by peak shifts in the respective RSMs. The triple crystal RSMs from these films, grown on a bulk Si substrate, $330 \mathrm{~nm}$ and $40 \mathrm{~nm}$ SOI substrates, are presented in Fig. 5. The degree of film relaxation, as indicated in the peak shift and peak width, is nearly identical for the $765 \mathrm{~nm}$ and $1200 \mathrm{~nm}$ thick films grown on all the various substrates. The only variation in the RSMs with a substrate is the shift in the position of the $\mathrm{Si}-\mathrm{SOI}$ diffraction peak. The peak from the bulk Si substrate is also broadened upon the growth of the SiGe film, similar to the $330 \mathrm{~nm}$ $\mathrm{Si}-\mathrm{SOI}$ layer, whereas the $40 \mathrm{~nm} \mathrm{Si-SOI}$ diffraction peak is below the detection limits of the x-ray measurement system. It is notable from these RSMs that the peak position of the $330 \mathrm{~nm} \mathrm{Si-SOI}$ peak is shifted to positive Bragg angles. Analysis of the $40 \mathrm{~nm}$ and $70 \mathrm{~nm}$ SOI samples, with the lower resolution but higher signal intensity detector slit, allows the shift of the diffraction peak from the thin $\mathrm{Si}-\mathrm{SOI}$ layer to positive Bragg angles to also be observed. This peak shift was not detectable in the $10000 \mathrm{~nm}$ SOI sample. A larger Si-SOI peak shift is observed for the $1200 \mathrm{~nm}$ film over the $765 \mathrm{~nm}$ film as expected from the greater strain relaxation in the $1200 \mathrm{~nm}$ film. This positive shift of Bragg angle indicates a reduction in the $\mathrm{Si}$-SOI out-of-plane lattice constant and a resultant tensile strain. Table II contains a summary of the x-ray data for the in situ relaxed samples. The full width at half maximum is measured in the tilt direction of Fig. 5.

TEM micrographs from the in situ relaxed samples confirm the presence of dislocations. Dislocations are also indicated by the crosshatch and the increased x-ray peak breadth observed for these samples. XTEM micrographs in Fig. 6 show a high density of misfit dislocations at the $\mathrm{SiGe} / \mathrm{Si}$ interface. Film threading dislocations are observed in all the samples as well as a high density of dislocations that extend and terminate at the buried oxide. As with the annealed samples, the dislocations that reach the oxide do not show any contrast in the TEM micrograph indicating that the strain field associated with the core of the misfit dislocations at the $\mathrm{Si} / \mathrm{SiO}_{2}$ interface has been largely dissipated. Additionally, stacking faults are present in all the thick relaxed films grown on both bulk Si and SOI substrates. The presence of stacking faults has been previously reported when relaxing highly strained films, such as $\mathrm{Ge}$ on relaxed $\mathrm{Si}_{0.70} \mathrm{Ge}_{0.30},{ }^{24}$ 

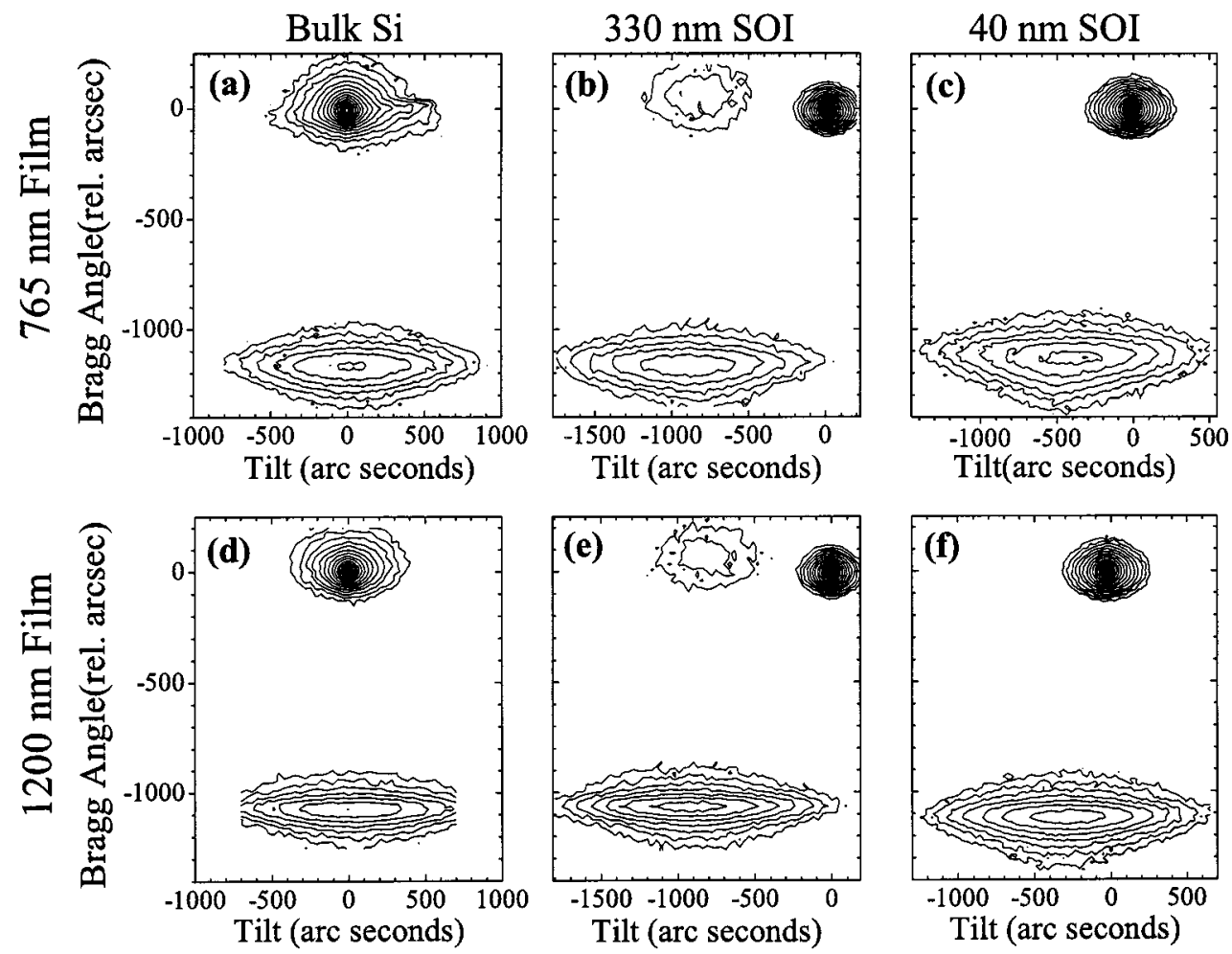

FIG. 5. Triple crystal RSMs of the (004) reflection of in situ relaxed films. The upper and lower rows were obtained from films grown to a thickness of 765 $\mathrm{nm}$ and $1200 \mathrm{~nm}$, respectively. From the left- to the right-hand side, the RSMs were determined from samples are grown on a bulk Si substrate, $330 \mathrm{~nm}$ SOI substrate, and $40 \mathrm{~nm}$ SOI substrate.

and in a graded $\mathrm{SiGe}$ buffer layer grown with a grading rate above $>27 \%$ per $\mu \mathrm{m} .{ }^{25}$ In the XTEM micrograph of Fig. 6(b), a stacking fault with at least six associated dislocations is observed. The density of dislocations indicates that the stacking fault strongly interacts with the threading dislocations. The PVTEM micrographs of the $1200 \mathrm{~nm}$ films re- laxed on bulk Si, $300 \mathrm{~nm} \mathrm{SOI}$, and $40 \mathrm{~nm} \mathrm{SOI}$, are shown in Fig. 7. These specimens were prepared by thinning from the substrate side so that only the SiGe film is imaged by TEM. All three samples have stacking faults and threading dislocations present. The blocking of dislocation motion by stacking faults, prevalent on all the substrates, increases the TDD

TABLE II. SiGe and Si-SOI layer strain data.

\begin{tabular}{|c|c|c|c|c|c|c|c|}
\hline $\begin{array}{l}\text { Film } \\
\text { thickness } \\
(\mathrm{nm})\end{array}$ & Substrate & $\begin{array}{c}\text { SiGe film } \\
\text { relaxation } \\
(\%)\end{array}$ & $\begin{array}{c}\text { SiGe } \\
\text { in-plane } \\
\% \\
\text { strain }\end{array}$ & $\begin{array}{l}\text { Dislocation } \\
\text { density } \\
(\mu \mathrm{m})\end{array}$ & $\begin{array}{c}\mathrm{Si}-\mathrm{SOI} \\
\text { in-plane } \\
\% \\
\text { strain }\end{array}$ & $\begin{array}{l}\text { Dislocation } \\
\text { density at } \\
\text { film } \backslash \text { substrate } \\
\text { interface } \\
(\mu \mathrm{m})\end{array}$ & $\begin{array}{c}\text { Dislocation } \\
\text { density at } \\
\mathrm{Si}-\mathrm{SOI} \backslash \mathrm{SiO}_{2} \\
\text { interface } \\
(\mu \mathrm{m})\end{array}$ \\
\hline 340 & $\begin{array}{c}330 \mathrm{~nm} \\
\text { SOI }\end{array}$ & 0 & -0.67 & 0 & 0 & 0.0 & 0.0 \\
\hline 340 & Bulk Si & 0 & -0.67 & 0 & $\ldots$ & 0.0 & 0.0 \\
\hline 765 & $\begin{array}{c}40 \mathrm{~nm} \\
\text { SOI }\end{array}$ & 76 & -0.16 & 27 & 0.196 & 10.0 & 17.0 \\
\hline 765 & $\begin{array}{c}70 \mathrm{~nm} \\
\text { SOI }\end{array}$ & 67 & -0.22 & 23 & 0.133 & 6.9 & 16.1 \\
\hline 765 & $\begin{array}{c}330 \mathrm{~nm} \\
\text { SOI }\end{array}$ & 72 & -0.20 & 24 & 0.0501 & 2.6 & 21.4 \\
\hline 765 & Bulk Si & 70 & -0.21 & 24 & $\cdots$ & $\cdots$ & $\cdots$ \\
\hline 1200 & $\begin{array}{c}40 \mathrm{~nm} \\
\text { SOI }\end{array}$ & 75 & -0.167 & 26 & 0.218 & 11.0 & 15.0 \\
\hline 1200 & $\begin{array}{c}70 \mathrm{~nm} \\
\text { SOI }\end{array}$ & 84 & -0.054 & 32 & $\cdots$ & $\cdots$ & $\cdots$ \\
\hline 1200 & $\begin{array}{c}330 \mathrm{~nm} \\
\text { SOI }\end{array}$ & 81 & -0.120 & 29 & 0.0693 & 3.6 & 25.4 \\
\hline 1200 & $\begin{array}{c}10 \mu \mathrm{m} \\
\text { SOI }\end{array}$ & & -0.154 & 27 & 0.0 & & \\
\hline 1200 & Bulk Si & & -0.074 & 32 & $\cdots$ & $\cdots$ & $\cdots$ \\
\hline
\end{tabular}


(a)

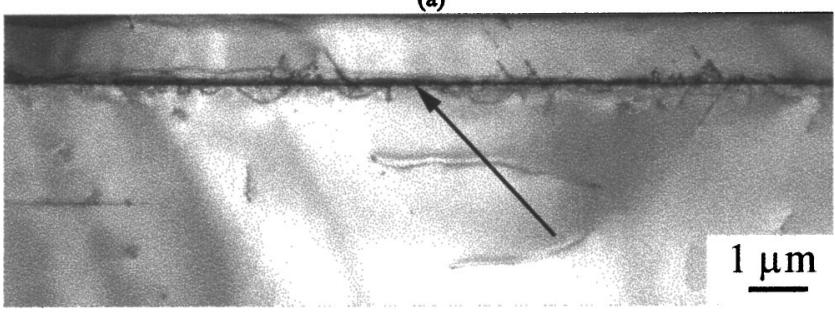

(b)

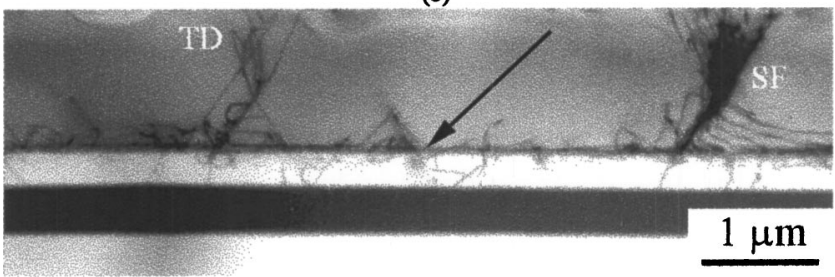

FIG. 6. Dislocation are observed in the XTEM micrographs obtained from the $1200 \mathrm{~nm} \mathrm{SiGe}$ films grown on (a) bulk Si and (b) $330 \mathrm{~nm}$ SOI substrates. $\mathrm{An}$ arrow indicates the placement of the $\mathrm{SiGe}-\mathrm{Si}$ interface. The stacking fault in (b) has accumulated at least six dislocations that have glided to it from the right-hand side.

which ranges from $10^{8} \mathrm{~cm}^{-2}$ on bulk $\mathrm{Si}$, to $5 \times 10^{7} \mathrm{~cm}^{-2}$ on $330 \mathrm{~nm} \mathrm{SOI}$, and $2 \times 10^{7} \mathrm{~cm}^{-2}$ on $40 \mathrm{~nm}$ SOI.

Many of the dislocations in the PVTEM micrographs lie on common glide planes. This arrangement is the product of a dislocation multiplication process during film relaxation, which has been previously observed in SiGe films. ${ }^{20,26}$ The buried oxide of the SOI substrate does not appear to interfere with these multiplication processes.

The AFM micrographs of all the in situ relaxed films exhibit the dislocation-derived crosshatch, as shown in Fig. 8. These films have a similar rms roughness ranging from 4.9 to $6.4 \mathrm{~nm}$. Morphological differences are observed, however, on a finer scale. All of the surface trenches run the full width of the scan range for the $\mathrm{SiGe}$ films grown on the bulk $\mathrm{Si}$ substrates. This behavior is also present on the $10000 \mathrm{~nm}$ SOI, which also has a high density of surface mounds. On the $330 \mathrm{~nm}$ and $40 \mathrm{~nm} \mathrm{Si}-\mathrm{SOI}$ substrates, only the deepest trenches run the length of the $10 \mu \mathrm{m}$ scans. Many shallow trenches run only a short distance. This is contrasted with the crosshatch structure of the films that relaxed during the $e x$ situ annealing shown in Fig. 3. All of these ex situ annealed films exhibited very long uniform trenches, which were only present on the in situ relaxed bulk Si and $10000 \mathrm{~nm} \mathrm{SOI}$ samples. Similar in situ observations were made using lowenergy electron microscopy, as described in Ref. 27.

\section{DISCUSSION AND MODELING}

\section{A. Film relaxation on silicon-on-insulator substrates}

The dependence of the SiGe film relaxation on both the temperature and film thickness for $\mathrm{Si}$ and SOI substrates, whether induced by high-temperature annealing or during growth, is essentially identical. In all cases, a large density of misfit dislocations at the $\mathrm{Si} / \mathrm{SiGe}$ interface are inferred from the increased x-ray diffraction peak width, the surface crosshatch, and, more directly, in the TEM micrographs. These
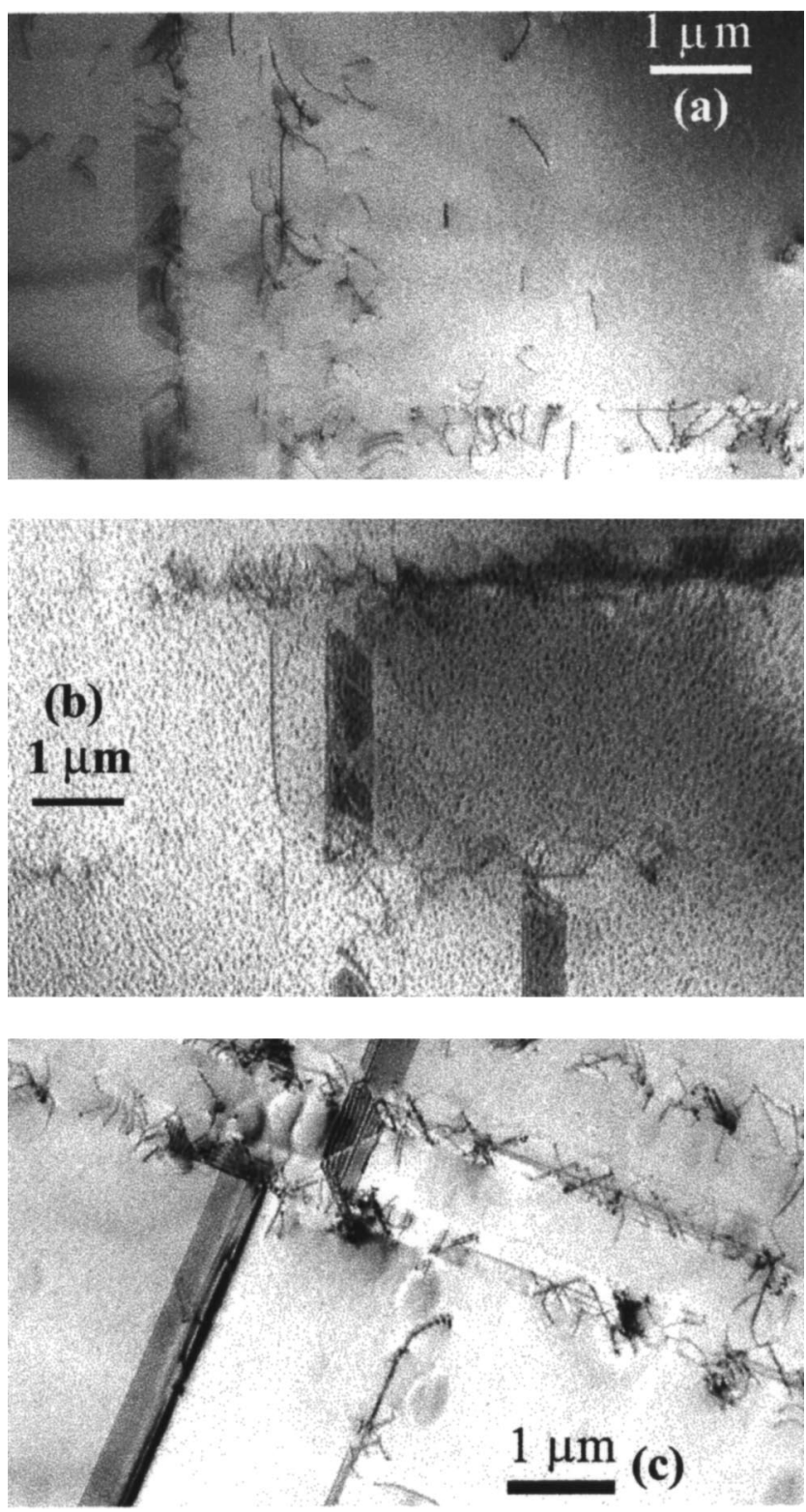

FIG. 7. PVTEM micrographs of the $1200 \mathrm{~nm} \mathrm{SiGe}$ films grown on (a) bulk $\mathrm{Si}$, (b) $330 \mathrm{~nm}$ SOI, (c) $40 \mathrm{~nm}$ SOI substrates in which the shaded rectangular regions are stacking faults present in these films.

results cannot be attributed to a compliant substrate mechanism, which would relax the film without the introduction of dislocations in the SiGe film. In addition, the amount of strain transfer to the $\mathrm{Si}-\mathrm{SOI}$ layer, required by the compliant substrate mechanism, was not observed in the x-ray diffraction. Compliant substrate theory predicts a tensile strain in the Si-SOI layer. This tensile strain is only observed in this study after extensive dislocation-based film relaxation. In both the ex situ and in situ samples, an appreciable dislocation density is also apparent from the diffraction peak width.

Compliant substrate strain sharing between the SiGe film and the Si-SOI layer was not present in any of the growth or annealing experiments. Film relaxation was only observed due to dislocation nucleation and propagation. Dislocations nucleate and propagate across the sample relaxing the film, with segments extending into the substrate. The dislocations in either the bulk $\mathrm{Si}$ or $\mathrm{Si}-\mathrm{SOI}$ layers are the product of the 


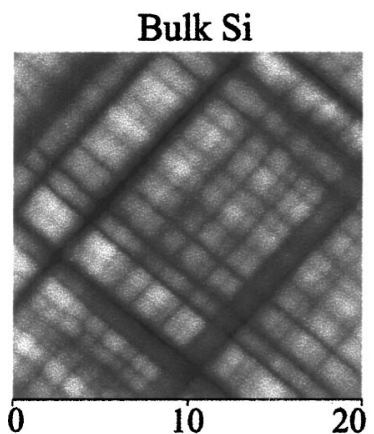

(a)

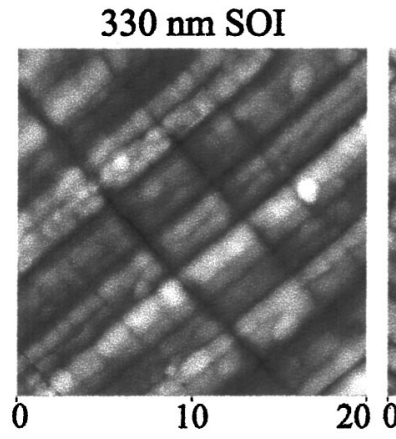

(c)
$10,000 \mathrm{~nm}$ SOI

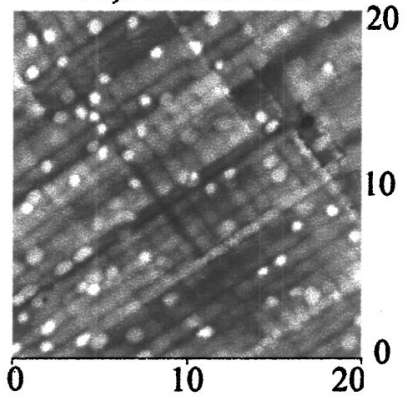

(b)

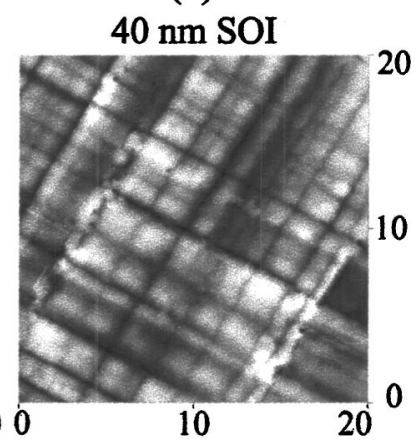

(d)
FIG. 8. AFM micrographs obtained from the in situ relaxed SiGe layers which were $1200 \mathrm{~nm}$ thick and grown on substrates consisting of (a) bulk Si, (b) a $10000 \mathrm{~nm}$ SOI substrate, (c) a $330 \mathrm{~nm}$ SOI substrate, and (d) a $40 \mathrm{~nm}$ SOI substrate. The long, even trenches apparent in Fig. 6(a) are contrasted with the much shorter shallower trenches in (c) and (d).

strong dislocation interactions, which push dislocations into the underlying layers. These dislocation interactions have been observed and modeled for a variety of cases including dislocation multiplication processes during perpendicular and parallel crossings of dislocations. ${ }^{20}$ The strain field interaction between dislocations provides the driving force to move the dislocations into the $\mathrm{Si}-\mathrm{SOI}$ layer and has a far greater influence on dislocation motion than the dislocation image force attributed to the buried oxide. ${ }^{15}$ On the SOI substrates, the dislocations penetrating into the $\mathrm{Si}-\mathrm{SOI}$ layer can reach the buried amorphous $\mathrm{Si}-\mathrm{SOI} /$ oxide interface. The substrate dislocations, pictured in the XTEM of the $40 \mathrm{~nm}$ Si-SOI layer in Fig. 4(b), all directly cross the layer and terminate at the oxide. In the $330 \mathrm{~nm} \mathrm{Si-SOI}$ layer in Fig. 6(b), the majority of the dislocations continue to reach the buried oxide layer. Throughout these series of samples, no dislocation-based contrast was observed at the $\mathrm{Si} / \mathrm{SiO}_{2}$ interface in the TEM micrographs. Therefore, the growth temperature of $630^{\circ} \mathrm{C}$ is sufficient for substantial dislocation core-spreading to occur during the film growth at this interface

This change in the dislocation structure occurs with no observed changes in the onset of film strain relaxation or the relaxation rate. This result suggests that the rate limiting steps governing film relaxation are largely taking place in the film and not in the substrate or at the film-substrate interface.

\section{B. Strain in the Si-Si-on-insulator layer}

Dislocation core-spreading has been observed, in situ, at interfaces between metals and amorphous layers. ${ }^{28-31}$ The lack of an extended crystal structure in the amorphous layer enables atomic motion, transforming the large and very local displacement of the dislocation core into smaller displacements spread along the interface through plastic deformation of the amorphous layer. ${ }^{32,33}$ This accommodation of the dislocation by the oxide reduces the strain, and ultimately removes the strain associated with the dislocation core and the accompanying dislocation line tension. This reduction in the dislocation line tension drives dislocation motion through the $\mathrm{Si}-\mathrm{SOI}$ layer.

The amount of misfit dislocation length transferred from the $\mathrm{SiGe} / \mathrm{Si}$ interface to the $\mathrm{Si} / \mathrm{SiO}_{2}$ interface can be experimentally determined from the change in strain of the layers. Each dislocation changes the lattice constant by an amount equal to the pure edge component of the Burger's vector in the plane of the interface. The $60^{\circ}$ dislocations found in the SiGe system have a Burger's vector of the type $a / 2$ [011], and the relevant edge component is $a / \sqrt{2}[110]=0.193 \mathrm{~nm}$. The average spacing of these dislocations can be determined from the change in in-plane strain of the layer: ${ }^{9}$

$$
\text { Dislocation Density }=\frac{\Delta \varepsilon}{\left|\mathbf{b}_{\text {edge }}\right|} .
$$

The calculated dislocation density is included in Table II. The observed $75 \%$ relaxation of the $1200 \mathrm{~nm}$ film on the 40 $\mathrm{nm}$ SOI substrate requires 26 dislocations per micron. The dislocation density can also be calculated for the dislocations that have moved across the $\mathrm{Si}-\mathrm{SOI}$ layer. The production of $0.22 \%$ strain in the $\mathrm{Si}-\mathrm{SOI}$ layer requires 11 dislocations per micron to have moved to the oxide interface, which leaves 15 dislocations per micron at the film/substrate interface. Similar dislocation densities exist at both interfaces, however, the dislocations at the crystalline interface are clearly visible in the XTEM micrographs, while they are not visible at the amorphous interface. The dislocation density at the amorphous interface varies between 2.6 to 11 per micron for the samples examined.

The dislocation loops extending into the bulk substrate will also cause a tensile strain to develop in the top microns of the Si substrate. In this case, there will be a broad distribution of strain states present in depth into the bulk Si substrate. Observation of this strain with an x ray is difficult due to the broad distribution of strain states over the diffraction sampling depth of tens of microns. In Fig. 5, the bulk substrate diffraction peak is clearly broader than the handle substrate of the SOI wafers. The diffracted intensity in the tail of the Si substrate peak is not symmetric with intensity broadening toward tensile-strained Si, i.e., positive Bragg angle.

\section{Equilibrium strain of Si-Si-on-insulator}

A schematic layout of the film and SOI substrate with respect to dislocation propagation is depicted in Fig. 9. A segment of the dislocation loop in the SiGe film has moved down to the $\mathrm{SiO}_{2}$ interface. The threading dislocation (TD) segments are labeled $\mathrm{TD}_{F}$ and $\mathrm{TD}_{S}$, which cross the $\mathrm{SiGe}$ 


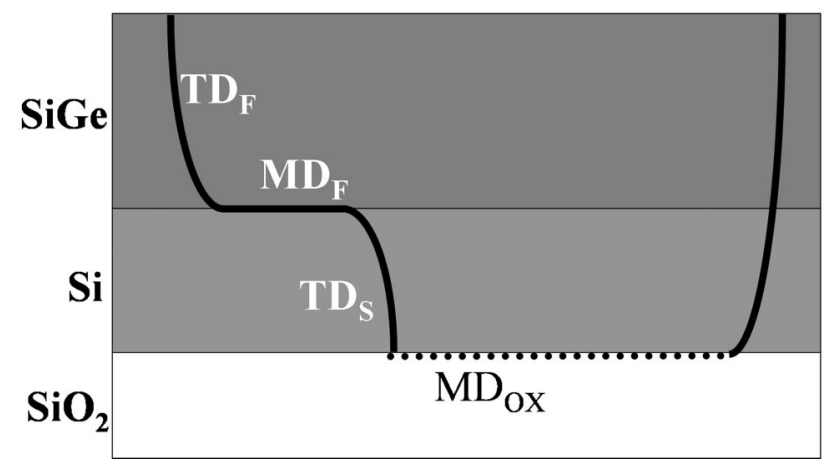

FIG. 9. Plot of the strain observed in the $\mathrm{Si}-\mathrm{SOI}$ layers following $\mathrm{SiGe}$ relaxation. The critical strain of Eq. (3) closely fits the data. The strain from neglecting the presence of the oxide layer is drawn dotted as well as the compliant substrate model, both overstate the observed strain.

film and $\mathrm{Si}$-SOI layer respectively. The film misfit dislocation $_{F}\left(\mathrm{MD}_{F}\right)$ is the conventional misfit dislocation lying at the $\mathrm{SiGe} / \mathrm{Si}$ interface, while $\mathrm{MD}_{\mathrm{OX}}$ is the misfit dislocation at the $\mathrm{SiO}_{2}$ interface. The right-hand side of the loop shows the possibility of $\mathrm{TD}_{F}$ and $\mathrm{TD}_{S}$ merging and removing $\mathrm{MD}_{F}$ from the interface. The dislocation energetics and resulting critical or equilibrium strains in the layers are discussed below.

The line tension of $\mathrm{MD}_{F}$ must be known in order to calculate the equilibrium strain of the $\mathrm{Si}-\mathrm{SOI}$ layer. The conventional dislocation line tension is defined by having the dislocation adjacent to a free surface and within an infinite substrate:

$$
F_{\mathrm{MD}_{F}}=\frac{\mu|\mathbf{b}|^{2}\left[1-\nu \cos ^{2}(\alpha)\right]}{4 \pi(1-\nu)} \ln \left(\frac{h_{F}}{|\mathbf{b}|}\right),
$$

where $\alpha$ is the angle between the Burger's vector and the dislocation line, $\mu$ is the shear modulus, $|\mathbf{b}|$ is the magnitude of the Burger's vector, $\nu$ is Poisson's ratio, and $h_{F}$ is the film thickness. It is important to note that the equations for the dislocation line tension are accurate to $\sim 20 \%$.

The dislocation line tension will be reduced by the local presence of the $\mathrm{SiO}_{2}$ layer on the SOI substrate, which has a smaller shear modulus, $0.333 \mathrm{GPa}$, than $\mathrm{Si}, 0.681 \mathrm{GPa}$. Dislocation core-spreading further reduces the strain in the oxide and decreases the dislocation line tension. Three different line tensions are calculated and evaluated against the experimental data. Equation (2) represents the upper limit for the line tension and is termed model 1 . The smaller shear modulus of the oxide can be accounted for in an approximate manner in model 2 by using the average shear modulus of the oxide and $\mathrm{Si}$ in Eq. (2). In model 3, the oxide interface is described as a free surface that is able to completely absorb the dislocation strain field while the core is tens of nanometers from the oxide interface. The line tension for this case of a dislocation in a free plate has been calculated to be: ${ }^{33}$

$$
F_{\mathrm{MD}_{F}}=\frac{\mu|\mathbf{b}|^{2}\left[1-\nu \cos ^{2}(\alpha)\right]}{4 \pi(1-\nu)} \ln \left(\frac{h_{S} h_{F}}{|\mathbf{b}|\left(h_{S}+h_{F}\right)}\right),
$$

where $h_{S}$ is the Si-SOI thickness. In the limit of a conventional substrate, $h_{S} \gg h_{F}$, Eq. (3) reduces to Eq. (2).

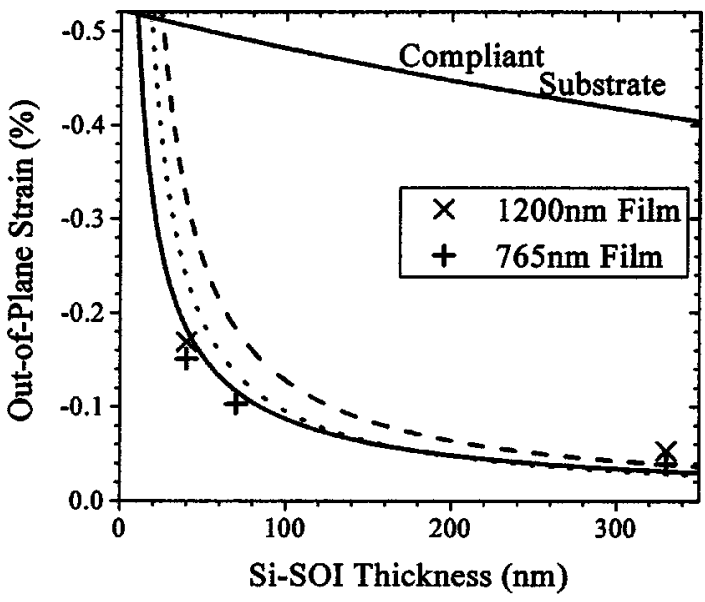

FIG. 10. Schematic of a misfit dislocation half-loop penetrating into the substrate. The threading and misfit dislocations are labeled, TD and MD respectively. Motion of the TDs determines the strain of the layers and the MD lengths.

The net force associated with the $\mathrm{Si}-\mathrm{SOI}$ layer strain, and the line tension of both $\mathrm{MD}_{\mathrm{OX}}$ and $\mathrm{MD}_{F}$ determine the motion of $\mathrm{TD}_{S}$ in the $\mathrm{Si}-\mathrm{SOI}$ layer. Initially, the strain in the $\mathrm{Si}-\mathrm{SOI}$ layer is zero, and the dislocation core spreading of the oxide reduces $\mathrm{MD}_{\mathrm{OX}}$ to zero. Therefore $\mathrm{TD}_{S}$ will move to the left-hand side in the diagram of Fig. 9.

The SiGe film relaxation evolves by moving $\mathrm{TD}_{F}$ to the left-hand side schematically in Fig. 9, which increases the in-plane lattice constant of the film. Left-hand sideward motion of $\mathrm{TD}_{S}$ within the $\mathrm{Si}-\mathrm{SOI}$ layer in Fig. 9 also increases the in-plane lattice constant of the $\mathrm{Si}-\mathrm{SOI}$ layer, subsequently producing a tensile strain in the $\mathrm{Si}-\mathrm{SOI}$ layer. This dislocation motion is the source of the tensile strain present in the $\mathrm{Si}-\mathrm{SOI}$ layer observed in Fig. 5. Misfit dislocation length will continue to be transferred from $\mathrm{MD}_{F}$ to $\mathrm{MD}_{\mathrm{OX}}$ as $\mathrm{TD}_{S}$ moves across the $\mathrm{Si}-\mathrm{SOI}$ layer, until the strain in the $\mathrm{Si}-\mathrm{SOI}$ is large enough to impede and stop the motion of $\mathrm{TD}_{S}$. The force on the threading dislocation from the film strain, $F_{\mathrm{TD}_{S}}$, is given by ${ }^{9}$

$$
F_{\mathrm{TD}_{S}}=\frac{\mu(1+\nu)}{(1-\nu)} \varepsilon_{s}|\mathbf{b}| h_{S},
$$

where $\varepsilon_{s}$ is the strain in the $\mathrm{Si}-\mathrm{SOI}$ layer. Equilibrium is established and $\mathrm{TD}_{S}$ stops moving when $F_{\mathrm{TD}_{S}}$ equals $F_{\mathrm{MD}_{F}}$. For model 3, where $F_{\mathrm{MD}_{F}}$ is the line tension for a dislocation in a free plate, Eq. (3), the equilibrium strain is given by

$$
\varepsilon^{*}=\frac{|\mathbf{b}|\left[1-\nu \cos ^{2}(\alpha)\right]}{4 \pi h_{S}(1+\nu)} \ln \left(\frac{h_{S} h_{F}}{|\mathbf{b}|\left(h_{S}+h_{F}\right)}\right) .
$$

A higher or lower strain state in the $\mathrm{Si}-\mathrm{SOI}$ layer would lead to $\mathrm{TD}_{S}$ motion allowing the layer to approach this equilibrium strain state. The calculated equilibrium strain according to these three models is plotted with the measured strain from the Si-SOI layers in Fig. 10. The lower three lines correspond to the three models presented above to describe the line tension of $\mathrm{MD}_{F}$. The solid dark line in Fig. 10 represents the results of model 3 in which the oxide behaves as a free surface represented in Eq. (5). The dotted line uti- 
lizes the average shear modulus of the oxide and the Si described in model 2, and the dashed line is for the case of an infinitely thick Si substrate, model 1 . The equilibrium strain of a perfectly compliant substrate, where the SiGe film and $\mathrm{Si}-\mathrm{SOI}$ layers are decoupled from the substrate, is also plotted in Fig. 10. In a compliant substrate, the mismatch strain is divided between the layers such that the strain of the SiGe and $\mathrm{Si}-\mathrm{SOI}$ layers is given $\mathrm{by}^{34}$

$$
\varepsilon_{S}=-\varepsilon_{m} \frac{h_{F}}{h_{S}+h_{F}}, \quad \varepsilon_{F}=\varepsilon_{m} \frac{h_{S}}{h_{S}+h_{F}},
$$

where $\varepsilon_{m}$ is the mismatch strain between $\mathrm{Si}$ and the SiGe film. A compliant substrate model predicts a much higher strain level in the $\mathrm{Si}-\mathrm{SOI}$ than was observed.

The equilibrium strain for the case of the infinite Si substrate, as well as the incorporation of the reduced shear modulus due to the softer oxide, over predict the observed strain. The best fit is obtained for model 3, which treats the oxide as a free surface. Several important conclusions can be reached from this analysis. The oxide is able to remove the line tension of $\mathrm{MD}_{\mathrm{OX}}$ at the oxide interface, and the fit of model 3 to the data suggests that the oxide is able to reduce the strain field of the dislocations that remain within a distance of 40 and $70 \mathrm{~nm}$ from the oxide interface. In order for these effects to occur, atoms in the oxide must be able to move and remove the strain in the oxide layer attributed to the line tension and strain field of the misfit dislocation. When the dislocation reaches the oxide interface, the oxide will be locally displaced by the length of the Burger's vector, $0.38 \mathrm{~nm}$. The oxide is capable of this local atomic-scale motion, evidenced by the lack of dislocation contrast at the amorphous interface in the XTEM micrographs. The atomic displacements at the oxide interface, resulting from dislocations at or near the oxide interface, need only be of the magnitude of a fraction of an Angstrom. The fit of model 3 suggests that the oxide is also able to undergo these small displacements at the growth temperature of $630^{\circ} \mathrm{C}$.

\section{Critical thickness for misfit dislocation formation}

A stated benefit of a compliant substrate has been the increase of the SiGe film critical thickness. Changes in the dislocation structure in the SOI substrate are not due to such compliant substrate behavior, but due to the buried oxide affecting the detailed energy and force balances governing dislocation motion. By reducing the $\mathrm{MD}_{F}$ line tension, the oxide stabilizes the formation of the misfit dislocation through the decrease in its energy, which has the effect of actually reducing the film critical thickness. Beyond a critical thickness, $\mathrm{TD}_{F}$ will glide and extend $\mathrm{MD}_{F}$. The forces on $\mathrm{TD}_{F}$ are the line tension of the $\mathrm{MD}_{F}$, from Eq. (3), and the film strain from Eq. (4). Equating these forces determines the critical thickness, $h_{F}^{*}$, to be

$$
h_{F}^{*}=\frac{|\mathbf{b}|\left[1-\nu \cos ^{2}(\alpha)\right]}{4 \pi \varepsilon_{F}(1+\nu)} \ln \left(\frac{h_{S} h_{F}^{*}}{|\mathbf{b}|\left(h_{S}+h_{F}^{*}\right)}\right) .
$$

The resulting critical thickness is plotted in Fig. 11 for $\mathrm{Si}-$ SOI thicknesses of $5 \mathrm{~nm}, 15 \mathrm{~nm}$, and a conventional substrate thickness of $500 \mu \mathrm{m}$. The reduction in the Si-SOI
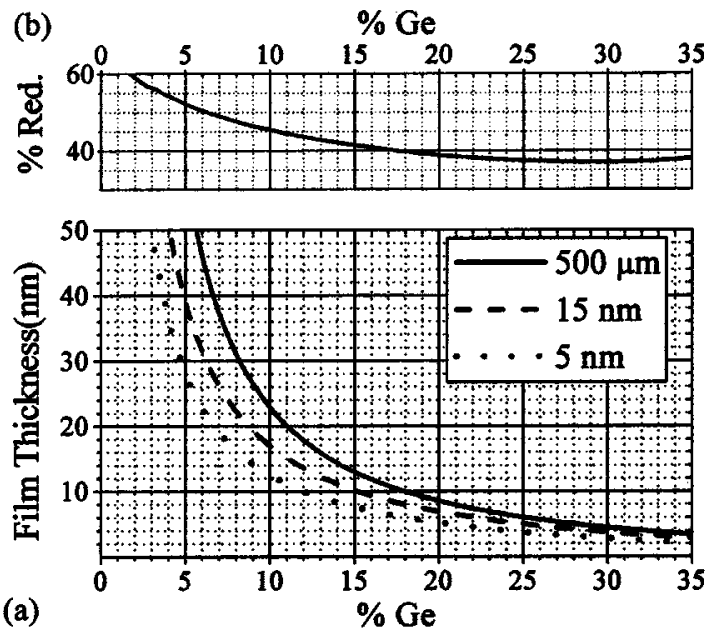

FIG. 11. Plot of the critical thickness for a strained film on a SOI substrate. Thinner substrate layers decrease the film critical thickness. The \% reduction of the critical thickness by a $5 \mathrm{~nm}$ is plotted in (b).

thickness decreases the film critical thickness by stabilizing the misfit dislocation formation. The percent of reduction of the critical thickness by the $5 \mathrm{~nm} \mathrm{Si-SOI}$ substrate is plotted in Fig. 11(b) and ranges from $35 \%$ to over $60 \%$.

\section{E. Relaxation without misfit dislocation formation}

The values of the critical thickness or strain of the SiGe film and $\mathrm{Si}-\mathrm{SOI}$ layer are derived from a force balance between the respective threading dislocation and $\mathrm{MD}_{F}$. These values will be altered if $\mathrm{MD}_{F}$ is not present and $\mathrm{TD}_{S}$ and $\mathrm{TD}_{F}$ merge into a single segment. In this case, there are no misfit dislocations at the $\mathrm{Si} / \mathrm{SiGe}$ interface as schematically described in the right-hand side half of Fig. 2. The layers will subsequently have a common in-plane lattice constant and the strain in the two layers would sum to the original mismatch strain between the $\mathrm{Si}$ and $\mathrm{SiGe}$

$$
\varepsilon_{m}=\varepsilon_{\mathrm{SiGe}}-\varepsilon_{\mathrm{Si}-\mathrm{SOI}} .
$$

Strain is transferred between the layers as a single threading segment moves within the bilayer. The equilibrium strain distribution is determined from the force balance on the TD in each layer coupled through Eq. (8). This result is the same equilibrium strain as the compliant substrate case of Eq. (6). The compliant substrate strain distribution is derived by setting the sum of the compressive and tensile stresses of the two layers to zero at equilibrium ${ }^{34}$

$$
\frac{2 \mu(1+\nu)}{(1-\nu)} \varepsilon_{S} h+\frac{2 \mu(1+\nu)}{(1-\nu)} \varepsilon_{F} h=0,
$$

allowing the mechanical constants to be the same for the $\mathrm{SiGe}$ and $\mathrm{Si}$.

The force on the TDs is this derived stress multiplied by the Burger's vector and the geometrical factor as expressed in Eq. (4). Since the Burger's vector and the TD orientation is the same in both layers, these terms cancel out, leading to the same strain distribution between the layers which is identical to the compliant substrate case. While the final strain 


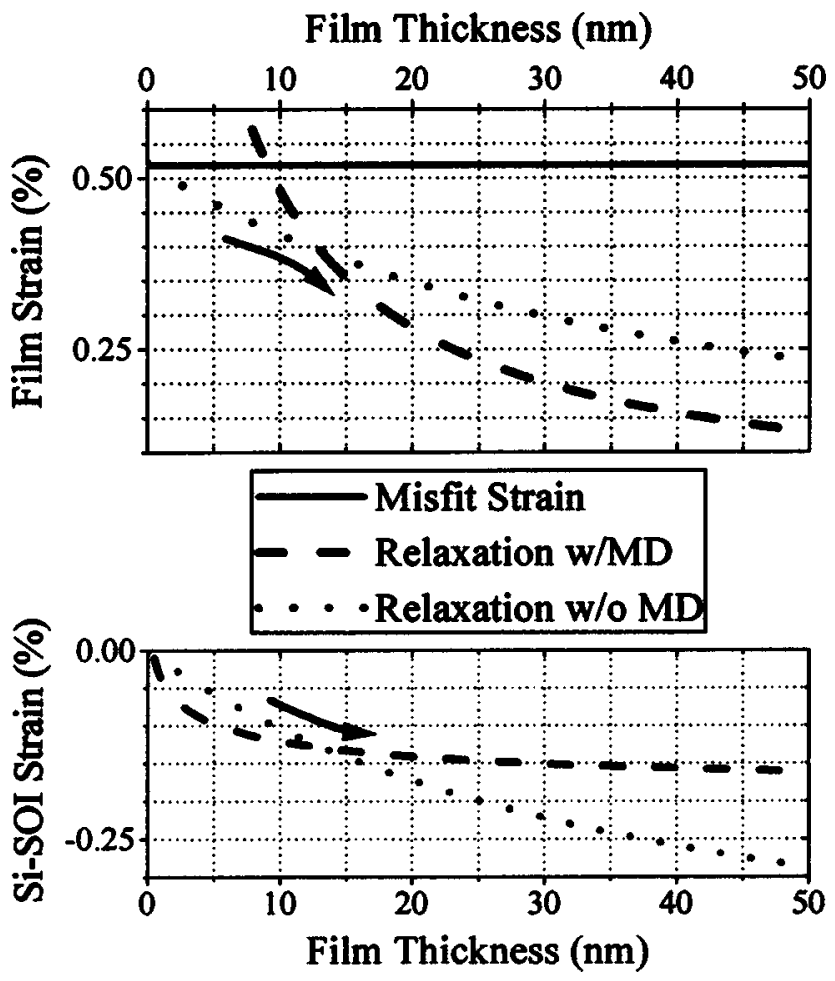

FIG. 12. Plot of strain as a function of thickness for a $\mathrm{Si}_{0.82} \mathrm{Ge}_{0.18}$ film on a $40 \mathrm{~nm} \mathrm{Si}-\mathrm{SOI}$ layer. The top half is the film strain, which is reduced due to dislocation motion with and without formation of a MD. The lower graph is the strain that develops in a $40 \mathrm{~nm} \mathrm{Si-SOI}$ layer.

states achieved for the compliant substrate and the model presented here are the same, the pathways to energy reduction are quite different.

The buried oxide, which allows TD motion and film relaxation without the formation of a misfit dislocation at the $\mathrm{SiGe} / \mathrm{Si}-\mathrm{SOI}$ interface, removes the constraint of a critical thickness for film relaxation. At any film thickness, it is energetically favorable to move dislocations and redistribute the strain according to Eq. (6). The SiGe film will initially relax by transferring strain to the $\mathrm{Si}-\mathrm{SOI}$ layer through the movement of the dislocation to the oxide interface. The $\mathrm{SiGe}$ is pseudomorphic to the Si-SOI during this stage of relaxation, and the in-plane lattice constant of both layers is increasing from the value for bulk silicon. Further deposition and relaxation of the strained film will exceed the critical strain of the $\mathrm{Si}-\mathrm{SOI}$ layer resulting in the extension of misfit dislocations at the $\mathrm{Si} / \mathrm{SiGe}$ interface instead of the oxide interface. At this point, the system is transitioning from the right- to the left-hand side half of Fig. 9.

Figure 12 is a plot of the possible strains for a $\mathrm{Si}_{0.82} \mathrm{Ge}_{0.18}$ film grown on a $40 \mathrm{~nm} \mathrm{Si-SOI}$ layer as a function of SiGe film thickness. The solid line is the mismatch strain between $\mathrm{Si}$ and $\mathrm{Si}_{0.82} \mathrm{Ge}_{0.18}$. The dotted line of Fig. 12 traces the strain distribution according to Eq. (6), while the dashed line is the equilibrium strain of the layers due to misfit dislocation extension, Eq. (5). The system will follow the pathway of least energy or strain. At the onset of growth, the strain in the $\mathrm{SiGe}$ layer will relax as the $\mathrm{Si}-\mathrm{SOI}$ becomes strained following the dotted lines in Fig. 12. The Si-SOI layer reaches its critical strain level at a SiGe film thickness of $13 \mathrm{~nm}$. $\mathrm{TD}_{S}$ of Fig. 9 will stop gliding, while $\mathrm{TD}_{F}$ continues to glide, which extends $\mathrm{MD}_{F}$. The layer strains are now following the dashed lines as $\mathrm{MD}_{F}$ extends at the $\mathrm{SiGe} /$ $\mathrm{Si}-\mathrm{SOI}$ interface.

Thinner Si-SOI layers will have the effect of shifting the crossover point to a greater film thickness. A $20 \mathrm{~nm} \mathrm{Si}-$ SOI layer would shift the point to $25 \mathrm{~nm}$ of SiGe film thickness while an $11 \mathrm{~nm} \mathrm{Si-SOI}$ layer would remove the crossover all together. At $11 \mathrm{~nm}$, the strain of an infinitely thick $\mathrm{Si}_{0.82} \mathrm{Ge}_{0.18}$ film can be transferred to the $\mathrm{Si}-\mathrm{SOI}$ without the formation of a misfit dislocation at the SiGe-to-Si-SOI interface.

The dislocation nucleation process is often a kinetically limited process, preventing film relaxation from following such equilibrium predictions. However, when threading dislocations are already present, the critical thickness is an accurate predictor of misfit dislocation formation. ${ }^{35} \mathrm{SiGe}$-onInsulator (SGOI) substrates have a TDD of $\sim 10^{6}$ per $\mathrm{cm}^{2}$ and have been fabricated as thin as $9 \mathrm{~nm} .{ }^{36}$ A strained Si film deposited on this SGOI substrate would be expected to follow the relaxation behavior described in Fig. 12.

\section{F. Effect on dislocation velocity}

The reduction in the dislocation strain field and line tension due to the buried amorphous layer can reduce the $\mathrm{SiGe}$ critical thickness and film strain. This phenomenon will also affect dislocation velocities in the layers. The equilibrium or critical strain occurs when the layer stress equals the line tension of the misfit dislocation. When these values are not equal, TDs in the layer move, bringing the layer toward the equilibrium strain state. The TD velocity is proportional to the difference between the film stress and line tension of the dislocation, which is defined as the excess stress. ${ }^{37,38}$ By decreasing or removing the line tension of the misfit dislocation, the buried amorphous oxide increases the magnitude of the excess stress and hence the dislocation velocity.

The buried amorphous layer will also increase the dislocation mobility, in addition to increasing the driving force for threading dislocation glide. Dislocation glide occurs by the nucleation of kinks, both by pairs of kinks within the film and single kinks from the film surface. The buried oxide provides a second interface for single kink nucleation. The oxide both increases the ease of kink formation as well as the driving force for kink formation, contributing to an increased dislocation velocity. Higher dislocation velocities will allow film relaxation to occur with a lower density of dislocations, providing for a reduced final threading dislocation density in the SiGe film.

These processes may explain the dislocation motion results of Dehm and Arzt. ${ }^{31}$ Their in situ TEM experiment observed dislocation loops in $\mathrm{Cu}$ meeting an amorphous $\mathrm{SiN}_{x}$ interface. The $\mathrm{Cu} / \mathrm{SiN}_{x}$ interface was described as a dislocation sink, removing dislocations from the TEM micrographs. The dislocation velocity was estimated at $3-25 \mathrm{~nm} / \mathrm{s}$, while moving and expanding within the $\mathrm{Cu}$ film. The dislocation velocity accelerated to greater than $50 \mathrm{~nm} / \mathrm{s}$ when the dislocation reached the $\mathrm{SiN}_{x}$ interface. The change in excess stress resulting from dislocation core spreading and addi- 
tional kink formation would lead to such an increase in dislocation velocity.

\section{CONCLUSIONS}

We have studied the SiGe relaxation on SOI substrates utilizing high temperatures to initiate relaxation of metastable films, as well as in situ relaxation of films by growth of the SiGe film to a thickness well beyond any critical thickness. SOI substrates used in this study had a thickness of 40 $\mathrm{nm}, 70 \mathrm{~nm}, 330 \mathrm{~nm}$, or $10000 \mathrm{~nm}$. On Si and SOI substrates, film relaxation was initiated at the same thickness or temperature, progressed at the same rate, and developed a crosshatched surface. The film TDD had a modest reduction from $10^{8} \mathrm{~cm}^{-2}$ on bulk Si to $5 \times 10^{7} \mathrm{~cm}^{-2}$ on $330 \mathrm{~nm} \mathrm{SOI}$, and $2 \times 10^{7} \mathrm{~cm}^{-2}$ on $40 \mathrm{~nm}$ SOI. No evidence of compliant substrate behavior was observed. While the crosshatch occurring for $\mathrm{SiGe}$ growth on a bulk $\mathrm{Si}$ substrate involves trenches running hundreds of microns in length, the crosshatch on SOI included some short trenches that were only a few microns in length. A primary structural difference between growths on bulk $\mathrm{Si}$ versus $\mathrm{Si}-\mathrm{SOI}$ layers was the development of strain in the $\mathrm{Si}-\mathrm{SOI}$ layer, which varied inversely with $\mathrm{Si}-\mathrm{SOI}$ layer thickness from $0.17 \%$ for the $40 \mathrm{~nm} \mathrm{Si}-$ SOI to 0 for both the $10000 \mathrm{~nm}$ SOI and bulk Si substrates. The strain in the $\mathrm{Si}-\mathrm{SOI}$ layer was modeled by describing the dislocation structure for the case where the $\mathrm{SiO}_{2}$ layer behaves as a free surface. Atomic motion within the oxide near the $\mathrm{Si}-\mathrm{SOI} /$ oxide interface would remove the dislocation strain field for dislocations at the oxide interface and within the $\mathrm{Si}-\mathrm{SOI}$ layer. The reduction in the dislocation strain fields decreases the dislocation line tension stabilizing misfit dislocation formation. The removal of the line tension of the dislocation at the oxide interface results in TD motion and film relaxation occurring without encountering an initial critical thickness limitation. The dislocation motion, changes in critical thickness, and the increased dislocation velocity derived from the response of the amorphous layer to the dislocation strain field should be observable in other heteroepitaxial systems incorporating strain and a buried or surface amorphous layer.

\section{ACKNOWLEDGMENTS}

D. Savage is gratefully acknowledged for his assistance and insightful discussions. This work was funded by the NSF-MRSEC at the University of Wisconsin-Madison, the ONR Program on Compliant substrates (C. Wood), and under DARPA/MTO Grant No. F33615-00-1-1720. In addition, A. Lal generously supplied the $10000 \mathrm{~nm}$ SOI substrates used in this work.
${ }^{1}$ C. G. Van de Walle and R. M. Martin, Phys. Rev. B 34, 5621 (1986).

${ }^{2}$ F. Schäaffler, Semicond. Sci. Technol. 12, 1515 (1997).

${ }^{3}$ P. See, D. J. Paul, B. Holländer, S. Mantl, I. V. Zozoulenka, and K.-F. Berggren, IEEE Electron Device Lett. 22, 182 (2001).

${ }^{4}$ D. A. Grotzmacher, T. O. Sedgwick, G. A. Northrop, A. Zaslavsky, A. R. Powell, and V. P. Kesan, J. Vac. Sci. Technol. B 11, 1083 (1993).

${ }^{5}$ E. A. Fitzgerald, Y.-H. Xie, D. Monroe, P. J. Silverman, J. M. Kuo, A. R. Kortan, F. A. Thiel, and B. E. Weir, J. Vac. Sci. Technol. B 10, 1807 (1992).

${ }^{6}$ K. Ismail, J. Vac. Sci. Technol. B 14, 2776 (1996).

${ }^{7}$ F. M. Ross, R. Hull, D. Bahnck, J. C. Bean, L. J. Peticolas, R. A. Ham, and H. A. Higgins, J. Vac. Sci. Technol. B 10, 2008 (1992).

${ }^{8}$ Y.-H. Xie, E. A. Fitzgerald, D. Monroe, G. P. Watson, and P. J. Silverman, Jpn. J. Appl. Phys., Part 1 33, 2372 (1994).

${ }^{9}$ E. A. Fitzgerald, Y.-H. Xie, M. L. Green, D. Brasen, A. R. Kortan, J. Michel, Y.-J. Mii, and B. E. Weir, Appl. Phys. Lett. 59, 811 (1991).

${ }^{10}$ P. I. Gaiduk, A. N. Larsen, and J. L. Hansen, Thin Solid Films 367, 120 (2000).

${ }^{11}$ F. K. Legoues, B. S. Meyerson, and J. F. Morar, Phys. Rev. Lett. 66, 2903 (1991).

${ }^{12}$ J. L. Liu, C. D. Moore, G. D. U'Ren, Y. H. Luo, Y. Lu, G. Jin, S. G. Thomas, M. S. Goorsky, and K. L. Wang, Appl. Phys. Lett. 75, 1586 (1999).

${ }^{13}$ A. R. Powell, S. S. Iyer, and F. K. LeGoues, Appl. Phys. Lett. 64, 1856 (1994).

${ }^{14}$ F. K. LeGoues, A. R. Powell, and S. S. Iyer, J. Appl. Phys. 75, 7240 (1994).

${ }^{15}$ Z. Yang, J. Alperin, W. I. Wang, S. S. Iyer, T. S. Kuan, and F. Semendy, J. Vac. Sci. Technol. B 16, 1489 (1998).

${ }^{16}$ E. M. Rehder, T. S. Kuan, and T. F. Kuech, Mater. Res. Soc. Symp. Proc. 673, 5.3.1 (2001).

${ }^{17}$ J. Tersoff and F. K. LeGoues, Phys. Rev. Lett. 72, 3570 (1994).

${ }^{18}$ H. Gao and W. D. Nix, Annu. Rev. Mater. Sci. 29, 173 (1999).

${ }^{19}$ S. Nayak, D. E. Savage, H. N. Chu, M. G. Lagally, and T. F. Kuech, J. Cryst. Growth 157, 168 (1995).

${ }^{20}$ K. W. Schwarz, J. Appl. Phys. 85, 120 (1999).

${ }^{21}$ M. Dollar and H. Gleiter, Scr. Metall. 20, 275 (1986).

${ }^{22}$ J. S. Liu and R. W. Balluffi, Mater. Res. Soc. Symp. Proc. 25, 261 (1984).

${ }^{23}$ P. Mullner and E. Arzt, Mater. Res. Soc. Symp. Proc. 505, 149 (1997).

${ }^{24}$ P. M. Mooney and J. O. Chu, Annu. Rev. Mater. Sci. 30, 335 (2000).

${ }^{25}$ M. Hohnisch, H.-J. Herzog, and F. Schäffler, J. Cryst. Growth 157, 126 (1995).

${ }^{26}$ W. Hagen and H. Strunk, Appl. Phys. 17, 85 (1978).

${ }^{27}$ A. R. Woll, P. Moran, E. M. Rehder, B. Yang, T. F. Kuech, and M. G. Lagally, Mater. Res. Soc. Symp. Proc. 696, 119 (2001).

${ }^{28}$ M. Dollar and H. Gleiter, Scr. Metall. 20, 275 (1986).

${ }^{29}$ J. S. Liu and R. W. Balluffi, Mater. Res. Soc. Symp. Proc. 25, 261 (1984).

${ }^{30}$ P. Mullner and E. Arzt, Mater. Res. Soc. Symp. Proc. 505, 149 (1997).

${ }^{31}$ G. Dehm and E. Arzt, Appl. Phys. Lett. 77, 1126 (2000).

${ }^{32}$ H. Gao, L. Zhang, and S. P. Baker, Mater. Res. Soc. Symp. Proc. 673, 6.6.1 (2001).

${ }^{33}$ O. Kraft, L. B. Freund, R. Phillips, and E. Arzt, Mater. Res. Bull. 27, 30 (2002).

${ }^{34}$ L. B. Freund and W. D. Nix, Appl. Phys. Lett. 69, 173 (1996).

${ }^{35}$ K. Ismail, F. K. LeGoues, K. L. Saenger, M. Arafa, J. O. Chu, P. M. Mooney, and B. S. Meyerson, Phys. Rev. Lett. 73, 3447 (1994).

${ }^{36}$ T. Tezuka, N. Sugiyama, and S. Takagi, Appl. Phys. Lett. 79, 1798 (2001).

${ }^{37}$ B. W. Dodson and J. Y. Tsao, Appl. Phys. Lett. 51, 1325 (1987).

${ }^{38}$ R. Hull, J. C. Bean, D. Bahnck, L. J. Peticolas, Jr., K. T. Short, and F. C. Unterwald, J. Appl. Phys. 70, 2052 (1991). 